\title{
Regulation of Placental Growth Hormone Secretion in a Human Trophoblast Model-The Effects of Hormones and Adipokines
}

\author{
WILLIBALD ZECK, CHARLOTTE WIDBERG, ERIN MAYLIN, GERNOT DESOYE, UWE LANG, DAVID MCINTYRE, \\ JOHN PRINS, AND ANTHONY RUSSELL
}

\begin{abstract}
Diamantina Institute for Cancer, Immunology and Metabolic Medicine [W.Z., C.W., E.M., D.M., J.P., A.R.], University of Queensland, South Brisbane, Queensland, 4102 QLD, Australia; and Department of Obstetrics and Gynecology [W.Z., G.D., U.L.], Medical University
\end{abstract} of Graz, Graz, Steiermark, 8036, Austria

\begin{abstract}
Placental growth hormone (PGH) is secreted from the human placental syncytiotrophoblast into the maternal circulation. PGH levels in pregnant women correlate with the birth weight of their offspring. We hypothesized that metabolic regulators may alter PGH secretion. BeWo cells as human trophoblast models were treated for 24, 48, and $72 \mathrm{~h}$ with insulin, insulin-like growth factor (IGF)-1, cortisol, ghrelin, leptin and visfatin. Cyclic-adenosinmonophosphate treatment served as positive control. PGH concentrations in culture media were measured. Insulin reduced $(p<0.008$; analysis of variance) PGH secretion from BeWo cells after $72 \mathrm{~h}$. No effect was found when treating cells with IGF-1. Cortisol reduced PGH secretion after $48 \mathrm{~h}(p<0.00118$; analysis of variance) and $72 \mathrm{~h}(p<$ $0.015)$. Leptin and ghrelin both suppressed $(p<0.027$ and $p<$ 0.017 , paired $t$ test) whereas visfatin increased ( $p<0.014$, paired $t$ test) PGH secretion at $72 \mathrm{~h}$. Cyclic adenosinmonophosphate increased $(p<0.003)$ PGH secretion at $72 \mathrm{~h}$. Our results indicate that in vitro $\mathrm{PGH}$ secretion by BeWo cells is regulated by hormonal factors and adipokines. We speculate on the existence of a maternalplacental regulatory loop, in which elevated insulin and leptin levels might down-regulate PGH secretion. (Pediatr Res 63: 353-357, 2008)
\end{abstract}

$\mathrm{P}$ acental growth hormone (PGH) is synthesized in and secreted from the human placental syncytiotrophoblast (1) into the maternal circulation in a nonpulsatile manner, detectable in the maternal circulation from gestational week 5 , and gradually increases in concentration throughout pregnancy. It has a short half-life and is undetectable $3 \mathrm{~h}$ after parturition (2). It is only found in the maternal, but not fetal circulation. Its maternal levels rise profoundly between weeks 20 and 30 of gestation, thus progressively replacing pituitary growth hormone in the human maternal circulation from midgestation onward (3-5). PGH has somatotropic effects, acting on liver and adipose tissue to influence gluconeogenesis and lipolysis to help ensure an adequate nutrient supply for the fetoplacental unit (6).

Previously, our group and others have shown a positive correlation between PGH levels in pregnant women and the birth weight of their offspring, stimulating discussions about its possible impact on fetal growth $(2,7)$. Understanding the regulation of fetal growth is important. According to the

Received August 6, 2007; accepted November 27, 2007

Correspondence: Willibald Zeck, M.D., M.Sc., Department of Obstetrics and Gynecology, Medical University of Graz, Austria, Auenbruggerplatz 14. A-8036 Graz, Austria; e-mail: willibald.zeck@meduni-graz.at
"Fetal Origins of Disease" hypothesis, it is well recognized that Type 2 diabetes mellitus (T2DM) and features of the metabolic syndrome are associated with birth weights at the extreme of the growth continuum (either small or large for gestational age) (8). The physiologic role of PGH in pregnancy is not completely understood, but its continuous secretion at high levels during pregnancy sparked speculation that it may be an important placental hormone affecting both mother and, indirectly, fetus (9). In vivo experiments have demonstrated that growth hormone, when infused into pregnant ewes late in gestation, can increase fetal growth (10). Transgenic mice overexpressing the human PGH gene become larger than their normal littermates and are hyperinsulinemic and insulin resistant (11). The relationship between fetal growth and PGH raises the possibility that PGH could be involved in the development of insulin resistance in pregnancy and might play an important role in gestational diabetes mellitus (GDM) and pregestational diabetes $(12,13)$.

The regulation of PGH secretion is very different from that of pituitary growth hormone (GH) as growth-hormone-releasing hormone does not modulate PGH in vivo. Furthermore, in vitro and in vivo studies have revealed that alterations in maternal nutrient (glucose) availability may alter PGH secretion (14). However, two decades have passed since the discovery of PGH, and still little is known about the regulation of its secretion.

We hypothesized that PGH secretion is regulated via several hormones and adipokines. As speculation, this regulation may lead to changes in PGH secretion in conditions associated with altered levels of hormones and adipokines such as in diabetic pregnancies. Thus, we selected hormones and adipokines, which are known to be closely related to fetal growth and adiposity, and tested their potential to act as PGH secretagauges: insulin as a potent stimulator of fetal growth and lipogenesis (15); IGF-1, which is related to increased birth size in diabetic pregnancies (16), and cortisol, also linked to fetal growth (17). Among the adipokines, we choose leptin, which is closely associated with fetal overgrowth (18) and reflects the mother's body fat mass (19), ghrelin, which, in low levels, is associated with increased insulin resistance and

Abbreviations: $\boldsymbol{\beta}$-HCG, beta-human chorionic gonadotropin; GDM, gestational diabetes mellitus; PGH, placental growth hormone 
inversely related to birth weight (20), and visfatin, which is altered in gestational diabetes (21).

BeWo cells, a human choriocarcinoma cell line, have proven as valuable cell model for the study of the cellular, molecular, and endocrine aspects of human trophoblasts (14). Because they secrete PGH, they were used in this study as in vitro system to identify regulators of PGH secretion.

\section{MATERIALS AND METHODS}

The study was conducted in accordance with the Guidelines in the Declaration of Helsinki and ethically approved by the Institutional Review Board.

Materials. BeWo cells were generously donated by Prof. R Mortimer's laboratory at the Royal Brisbane and Women's Hospital in Brisbane and were originally purchased from the American Tissue Culture Collection (ATCC, Rockville, MD; ATCC no. CCL98; used at passages 25-30). Reagents for cell culture were supplied by Invitrogen Life Technologies (Sydney, Australia). T $75 \mathrm{~cm}^{2}$ flasks and 12-well cell culture plates were obtained from Corning Incorporated (New York, NY). Placental growth hormone enzyme-linked immunosorbent assay (ELISA) kits were purchased from Diagnostic Systems Laboratories (DSL, Webster, TX). OD of the samples was measured in a Multiskan plate reader (Thermo Labsystems, Stockholm, Finland). Betahuman chorionic gonadotropin $(\beta$-HCG) concentrations were measured using an immunoassay analyzer (Advia Centaur Immunoassay System, Bayer Diagnostics, Munich, Germany). The amount of cellular protein was determined using a bicinchoninic acid protein assay kit from Pierce Biotechnology (Rockford, IL). Human insulin, cortisol, human recombinant leptin, and cyclic adenosinmonophosphate (cAMP) were purchased from Sigma Chemical Co. Aldrich Inc. (St. Louis, MO), human ghrelin from Bachem AG (Bubendorf, Switzerland) and human IGF-1 from R\&D (Minneapolis, MN).

Cell culture. BeWo cells were plated in $\mathrm{T} 75 \mathrm{~cm}^{2}$ flasks (seeding 650,000 cells $/ \mathrm{mL}$ ), cultured in Ham F-12 K nutrient mixture (Kaighn Modification) supplemented with $15 \%$ fetal calf serum (FCS), $1 \%$ penicillin/streptomycin, $1 \% \mathrm{~L}$-glutamine and $2 \%$ sodium bicarbonate, at $37^{\circ} \mathrm{C}$ in a humidified incubator with $5 \% \mathrm{CO}_{2}$ and grown to $70 \%-80 \%$ confluence.

Cell treatment. After seeding, the cells $(950,000$ cells per well) into 12-well plates, they were treated with insulin, IGF-1, cortisol, leptin, ghrelin, and visfatin. cAMP induces cell differentiation (22), served as a positive control, and was therefore used to monitor cell viability during treatment. Because previous studies have shown that glucose alters PGH secretion (23), cells were grown in Dulbecco's Modified Eagle Medium/No Glucose during treatment supplemented by $10 \%$ FCS and 1\% L-glutamine. FCS was added to the Dulbecco's Modified Eagle Medium, because pilot experiments had revealed that during time courses in serum-free medium of more than $24 \mathrm{~h}$ BeWo cells would lose viability. Both time- $(24,48$, and $72 \mathrm{~h})$ and dosecourse experiments within, below, and above physiologic concentrations were conducted. During the treatment period cells were kept at $37^{\circ} \mathrm{C}$ in a humidified incubator with $5 \% \mathrm{CO}_{2}$.

Placental growth hormone quantitation. The cell media was collected at 24, 48 , and $72 \mathrm{~h}$ after treatment and PGH was quantitated by ELISA. Samples were measured in a plate reader and absorption read at $450 \mathrm{~nm}$ with background wavelength correction set at $620 \mathrm{~nm}$. The sensitivity of the assay is $8 \mathrm{pg} / \mathrm{mL}$. The intra-assay and interassay coefficients of variation were $4.7 \%$ and $6.2 \%$, respectively. The mean absorbance of two duplicates was calculated for each standard, control and unknown. At the end of each incubation period cell lysates were washed with phosphate-buffered saline (PBS), extracted from the 12-well culture plates, and cell protein content was measured. Data obtained from ELISA was corrected for cell lysate protein content.

Statistical analysis. Within an experiment, treatments were measured in duplicate and experiments were performed 3-5 times. Data are represented as the mean $\pm \mathrm{SD}(\mathrm{SD})$. To correct for baseline differences between experiments, the effect of treatment was expressed as a percentage of the control performed for each experiment. Analysis of variance (ANOVA) was used to analyze for treatment effects followed by Tukey's multiple comparison test as post hoc test when appropriate. Comparison between treatment and control was analyzed by a Student's paired $t$ test. A level of $p<0.05$ was considered significant.

\section{RESULTS}

cAMP treatment resulted in increased secretion of $\beta$-HCG into the media indicating differentiation of the BeWo cells as

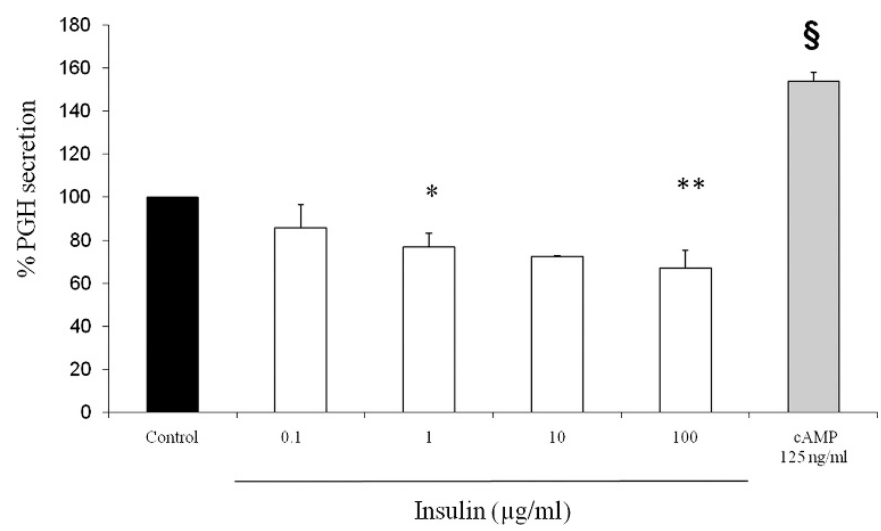

Figure 1. Dose-dependent suppression of PGH secretion in BeWo cells after insulin treatment $(72 \mathrm{~h})$, ANOVA $p=0.008 ; * p<0.05$, ** $p<0.01$, (Tukey's multiple comparison test). cAMP treatment resulted in up-regulated PGH secretion, $\S p=0.003$ (paired $t$ test), $n=4$ individual experiments each run in duplicates.

previously reported by others (24) and therefore served as a positive control for viability. PGH secretion was also increased by cAMP ( $p=0.003$ ) (Fig. 1).

Insulin suppressed PGH secretion from BeWo cells at $72 \mathrm{~h}$ in a dose-dependent fashion (ANOVA $p=0.008$ ) with a $33 \pm$ $8 \%$ suppression at $100 \mu \mathrm{g} / \mathrm{mL}(p<0.01)$ (Fig. 1). PGH secretion was not altered by IGF-1 at concentrations of 100 , 200, 400 and $800 \mathrm{ng} / \mathrm{mL}$ (data not shown). Cortisol dosedependently reduced PGH secretion in BeWo cells at $72 \mathrm{~h}$ (ANOVA $p=0.015$ ) with $38 \pm 19 \%$ suppression at a concentration of $100 \mu \mathrm{g} / \mathrm{dL}(p<0.05)$ (Fig. 2). A similar effect (ANOVA $p=0.0118$ ) was found already at $48 \mathrm{~h}$ at concentrations of 5,25 , and $50 \mu \mathrm{g} / \mathrm{dL}$ (data not shown).

Both leptin and ghrelin showed a tendency toward a dosedependent suppression of PGH secretion at $72 \mathrm{~h}$ without reaching significance for treatment (ANOVA $p=0.183$ and $=0.193$, respectively; data not shown). However, at $72 \mathrm{~h}$ both leptin $(50 \mathrm{ng} / \mathrm{mL})$ and ghrelin $(0.1 \mathrm{ng} / \mathrm{mL})$ suppressed PGH secretion significantly by $10 \pm 6 \%(p=0.027)$ and $18 \pm$ $7 \%(p=0.017)$, respectively (Fig. 3). Conversely, visfatin tended to dose-dependently increase PGH secretion at $72 \mathrm{~h}$ without reaching significance (ANOVA $p=0.148$ ) (Fig. 4).

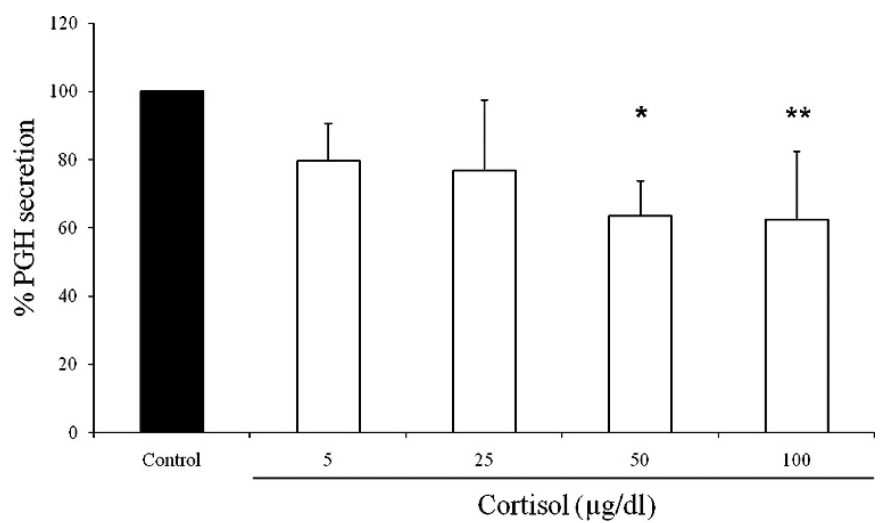

Figure 2. Dose-dependent suppression of PGH secretion in BeWo cells after cortisol treatment $(72 \mathrm{~h})$, ANOVA $p=0.015$, Tukey's multiple comparison test: $* p<0.05, * * p<0.05, n=3$ individual experiments each run in duplicates. 


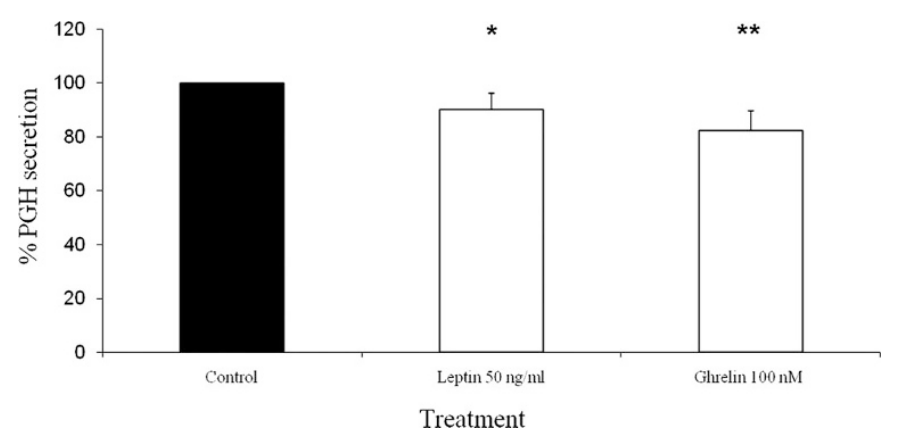

Figure 3. PGH secretion in BeWo cells after leptin $\left({ }^{*} p<0.05\right)$ and ghrelin $(* * p<0.05)$ treatment $(72 \mathrm{~h})$, (paired $t$ test), $n=4$ individual experiments each run in duplicates.

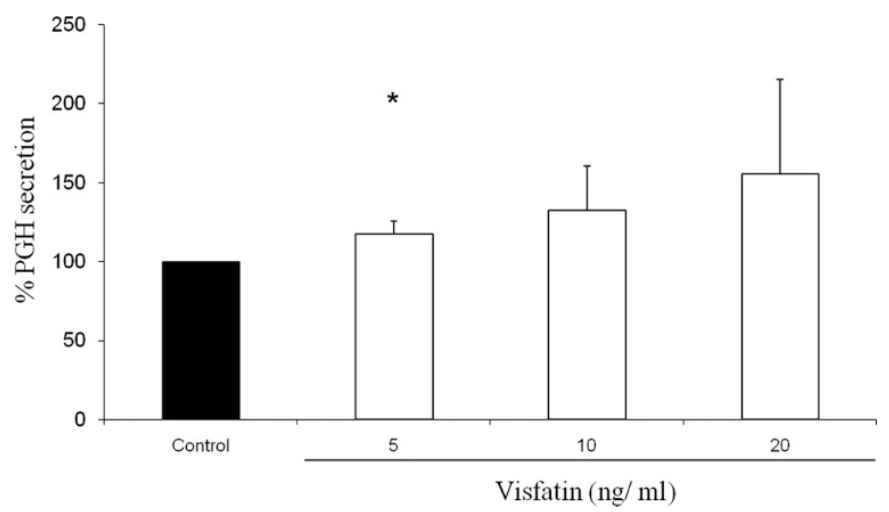

Figure 4. Dose-dependent increase of PGH secretion in BeWo cells after visfatin treatment $(72 \mathrm{~h})$, ANOVA $p=0.148$; Tukey's multiple comparison test: $* p<0.05$ ), (paired $t$ test), $n=4$ individual experiments each run in duplicates.

However, after $72 \mathrm{~h}$ visfatin increased PGH secretion significantly by $18 \pm 8 \%(p=0.014)$ at a concentration of $5 \mathrm{ng} / \mathrm{mL}$.

None of the hormones and adipokines altered $\beta$-HCG secretion into the media (data not shown). Over the time period of the experiments, i.e., up to $72 \mathrm{~h}$, no changes of PGH levels in the culture medium of the controls were observed.

\section{DISCUSSION}

The present study demonstrates for the first time that PGH secretion is regulated in vitro by a number of hormones and adipokines. In the past, serum level of hormones, adipokines, and PGH in pregnancy and their relationship to fetal growth have been investigated by correlation analyses (25), but to the best of our knowledge, a direct effect of hormones or adipokines on PGH secretion in vitro has never been studied.

Most treatments have resulted in suppression of PGH secretion. Because this could be accounted for by reduced functional activity of the cells, cell viability was carefully monitored. This was also necessary, because the cells were cultured in the absence of glucose to avoid any crossregulation (22). Differentiation of the cells by cAMPtreatment (23) (Fig. 1) was accompanied by the well-known elevation of $\beta$-HCG levels in the culture medium. PGH levels also increased to a similar extent as $\beta$-HCG, demonstrating that PGH secretion increases with differentiation of BeWo cells. Like in the controls, none of the treatments altered $\beta$-hCG secretion over the time course of the experiments. Therefore, we conclude that the cells maintained their functional viability and that neither PGH nor any of the treatments alters the differentiation status of the cells. Functional integrity of the cells is also indirectly reflected by the stimulatory effect of visfatin on PGH secretion.

The insulin-induced suppression of PGH secretion is an important observation. The underlying mechanism is unclear, but preliminary data using the PI3-kinase inhibitor LY294002 showed an even bigger inhibitory effect of insulin (not shown). If confirmed this would strongly argue for a PI3kinase-independent insulin effect. In vivo trophoblast insulin receptors are located exclusively at the microvillous membrane of the syncytiotrophoblast $(26,27)$. This location strongly argues for the maternal circulation as the sole insulin source regulating PGH secretion. PGH can cause insulin resistance by changing the subunit composition of phosphatidylinositol 3-kinase17 (11). The contribution of PGH to maternal insulin resistance makes it tempting to hypothesize a maternalplacental feedforward-feedback loop as proposed recently (28). In this model, elevated insulin levels associated with insulin resistance would lead to a reduced PGH secretion, a contributing factor to this condition, which in turn would alleviate insulin resistance. It remains to be determined whether insulin resistance often associated with maternal obesity or pregnancies complicated by gestational or Type-2 diabetes reflects dysregulation of this insulin-PGH feedback loop.

In contrast to insulin, IGF-1 had no significant effect in our experiments. Insulin and IGF-1 can stimulate each other's receptors at different potencies (29). Absence of IGF-1 effect in BeWo cells that express IGF-I receptors and respond to IGF-1 (30), suggests specific signaling of the insulin effect through insulin receptors only. IGF-1 and growth hormone are often involved in feedback loops with opposing actionsoften described as "direct" and "indirect" growth hormone effects (31). Our data might suggest there is no feedback system of IGF-1 on PGH secretion in vivo. However, this has to be confirmed in primary human trophoblast cells.

We have shown for the first time that cortisol treatment of BeWo cells decreases PGH secretion into the cell media (Fig. $2)$. The concentration range chosen included the range of cortisol levels present in cord blood in in vivo studies (13-23 $\mu \mathrm{g} / \mathrm{dL}$ ) (32). Previous studies in lambs have suggested that application of repetitive maternal glucocorticoid exposure leads to symmetric growth retardation in lambs delivered prematurely and a decreased fetal size persisted to term (33). Furthermore, increased cortisol levels have been noted in SGA fetuses (34). Further experiments are necessary to help understand the significance of the findings for pregnancy and fetal growth.

The expression of leptin receptor transcripts in the syncytiotrophoblast makes the placenta one of the target tissues for leptin. The suppression of PGH in vitro after treatment with leptin conforms to in vivo studies identifying maternal leptin as a negative predictor of PGH (35). Increased leptin levels are found in obese pregnant women, who have a higher risk of adverse pregnancy outcomes including gestational diabetes (36). The treatment effect was not significant at $72 \mathrm{~h}$, but was 
significant at the highest concentration tested $(50 \mathrm{ng} / \mathrm{mL})$, a level which occurs in very obese pregnant women (37). This suggests that a concentration range up to much higher concentrations might have resulted also in significance of the treatment effect. As both insulin and leptin have similar effects of PGH suppression, it is possible that both regulate PGH secretion in a diabetic and/or obese metabolic state.

Ghrelin has been discovered as a hormone related to pituitary growth hormone secretion, but is also recognized as an anorexogenic hormone with elevated levels increasing appetite. However, ghrelin's role in pregnancy is far from understood (19). Recently, ghrelin was found in cord blood samples with increased levels in smaller fetuses $(18,38)$. However, the consequences of the direct suppressive effect of ghrelin on PGH as found are unclear at present.

Visfatin treatment resulted in a nonsignificant tendency toward a dose-dependent increase of PGH secretion at $72 \mathrm{~h}$ (Fig. 4). Concentrations here resembled those of maternal venous blood in GDM pregnancies between the 24th and 28th week of gestation, which are lower in GDM women than in a healthy control group (38), although elevated visfatin levels in GDM women were also found (20). The significance, if any, for normal or GDM pregnancies of the present findings remains to be determined in future studies.

In conclusion, our data indicate that PGH secretion in BeWo cells that serve as a model for human trophoblast can be regulated in vitro by a number of adipokines and hormones. These results are in line with previous in vivo studies and lead us to conclude that PGH may be directly regulated by certain factors rather than just associated with these factors as previously demonstrated in vivo. Although the present study was not designed to identify the fetal or maternal origin of the regulation in some instances the placental location of the hormone or adipokine receptors demonstrated in other studies has allowed some conclusions. Further in vitro and in vivo experiments are warranted. It remains to be determined whether the effects of adipokines and hormones on PGH secretion are altered in pregnancies associated with diabetes and altered fetal growth.

Acknowledgments. The authors thank Prof. R Mortimer from the Royal Brisbane and Women's Hospital in Brisbane, Australia, for providing the BeWo cells as well as Dr. Goce Dimeski from the Pathology Department at the Princess Alexandra Hospital in Brisbane for $\beta$-HCG determinations.

\section{REFERENCES}

1. Scippo ML, Frankenne F, Hooghe-Peters EL, Igout A, Velkeniers B, Hennen G 1993 Syncytiotrophoblastic localization of the human growth hormone variant mRNA in the placenta. Mol Cell Endocrinol 92:R7-R13

2. Chellakooty M, Vangsgaard K, Larsen T, Scheike T, Falck-Larsen J, Legarth J, Andersson AM, Main KM, Skakkebaek NE, Juul A 2004 A longitudinal study of intrauterine growth and the placental growth hormone $(\mathrm{GH})$-insulin-like growth factor I axis in maternal circulation: association between placental $\mathrm{GH}$ and fetal growth. J Clin Endocrinol Metab 89:384-391

3. McIntyre HD, Russell A, Serek R, Veveris-Lowe T, Cotterill A, Cowley D, Barnard R 2002 Placental growth hormone is not suppressed by oral glucose loading in normal human pregnancy. Horm Metab Res 34:250-253

4. Frankenne F, Closset J, Gomez F, Scippo ML, Smal J, Hennen G 1988 The physiology of growth hormones (GHs) in pregnant women and partial characterization of the placental GH variant. J Clin Endocrinol Metab 66:1171-1180
5. Wu Z, Bidlingmaier M, Friess SC, Kirk SE, Buchinger P, Schiessl B, Strasburger CJ 2003 A new nonisotopic, highly sensitive assay for the measurement of human placental growth hormone: development and clinical implications. J Clin Endocrinol Metab 88:804-811

6. Jorgensen JO, Pedersen SA, Thuesen L, Jorgensen J, Ingemann-Hansen T, Skakkebaek NE, Christiansen JS 1989 Beneficial effects of growth hormone treatment in GH-deficient adults. Lancet 1:1221-1225

7. McIntyre HD, Serek R, Crane DI, Veveris-Lowe T, Parry A, Johnson S, Leung KC, Ho KK, Bougoussa M, Hennen G, Igout A, Chan FY, Cowley D, Cotterill A, Barnard R 2000 Placental growth hormone (GH), GH-binding protein, and insulinlike growth factor axis in normal, growth-retarded, and diabetic pregnancies: correlations with fetal growth. J Clin Endocrinol Metab 85:1143-1150

8. Barker DJ, Osmond C, Golding J, Kuh D, Wadsworth ME 1989 Growth in utero, blood pressure in childhood and adult life, and mortality from cardiovascular disease. BMJ 298:564-567

9. Lacroix MC, Guibourdenche J, Frendo JL, Pidoux G, Evain-Brion D 2002 Placental growth hormones. Endocrine 19:73-79

10. Jenkinson CM, Min SH, Mackenzie DD, McCutcheon SN, Breier BH, Gluckman PD 1999 Placental development and fetal growth in growth hormone-treated ewes. Growth Horm IGF Res 9:11-17

11. Barbour LA, Shao J, Qiao L, Pulawa LK, Jensen DR, Bartke A, Garrity M, Draznin B, Friedman JE 2002 Human placental growth hormone causes severe insulin resistance in transgenic mice. Am J Obstet Gynecol 186:512-517

12. Kjos SL, Buchanan TA 1999 Gestational diabetes mellitus. N Engl J Med 341:1749_ 1756

13. Macintosh MC, Fleming KM, Bailey JA, Doyle P, Modder J, Acolet D, Golightly S, Miller A 2006 Perinatal mortality and congenital anomalies in babies of women with type 1 or type 2 diabetes in England, Wales, and Northern Ireland: population based study. BMJ 333:177-179

14. Alsat E, Guibourdenche J, Luton D, Frankenne F, Evain-Brion D 1997 Human placental growth hormone. Am J Obstet Gynecol 177:1526-1534

15. Lindsay RS, Hamilton BA, Calder AA, Johnstone FD, Walker JD 2004 Scottish Multicentre Study of Diabetes in Pregnancy. The relation of insulin, leptin and IGF-1 to birthweight in offspring of women with type 1 diabetes. Clin Endocrinol (Oxf) 61:353-359

16. Lindsay RS, Westgate JA, Beattie J, Pattison NS, Gamble G, Mildenhall LF, Breier $\mathrm{BH}$, Johnstone FD 2007 Inverse changes in fetal insulin-like growth factor (IGF)-1 and IGF binding protein-1 in association with higher birth weight in maternal diabetes. Clin Endocrinol (Oxf) 66:322-328

17. Barbour LA, Shao J, Qiao L, Leitner W, Anderson M, Friedman JE, Draznin B 2004 Human placental growth hormone increases expression of the $\mathrm{p} 85$ regulatory unit of phosphatidylinositol 3-kinase and triggers severe insulin resistance in skeletal muscle. Endocrinology 145:1144-1150

18. Wolf HJ, Ebenbichler CF, Huter O, Bodner J, Lechleitner M, Foger B, Patsch JR, Desoye G 2000 Fetal leptin and insulin levels only correlate in large-for-gestational age infants. Eur J Endocrinol 142:623-629

19. Gualillo O, Caminos J, Blanco M, Garcia-Caballero T, Kojima M, Kangawa K, Dieguez C, Casanueva F 2001 Ghrelin, a novel placental-derived hormone. Endocrinology 142:788-794

20. Fuglsang J, Sandager P, Møller N, Fisker S, Frystyk J, Ovesen P 2006 Peripartum maternal and foetal ghrelin, growth hormones, IGFs and insulin interrelations. Clin Endocrinol (Oxf) 64:502-509

21. Krzyzanowska K, Krugluger W, Mittermayer F, Rahman R, Haider D, Shnawa N, Schernthaner G 2006 Increased visfatin concentrations in women with gestational diabetes mellitus. Clin Sci (Lond) 110:605-609

22. Hohn HP, Linke M, Ugele B, Denker HW 1998 Differentiation markers and invasiveness: discordant regulation in normal trophoblast and choriocarcinoma cells. Exp Cell Res 244:249-258

23. Patel N, Alsat E, Igout A, Baron F, Hennen G, Porquet D, Evain-Brion D 1995 Glucose inhibits human placental GH secretion, in vitro. J Clin Endocrinol Metab 80:1743-1746

24. Ogura K, Sakata M, Okamoto Y, Yasui Y, Tadokoro C, Yoshimoto Y, Yamaguchi M, Kurachi H, Maeda T, Murata Y 2000 8-bromo-cyclicAMP stimulates glucose transporter-1 expression in a human choriocarcinoma cell line. J Endocrinol 164:171-178

25. Verhaeghe J, van Bree R, Van Herck E 2006 Maternal body size and birth weight: can insulin or adipokines do better? Metabolism 55:339-344

26. Desoye G, Hofmann HH, Weiss PA 1992 Insulin binding to trophoblast plasma membranes and placental glycogen content in well-controlled gestational diabetic women treated with diet or insulin, in well-controlled overt diabetic patients and in healthy control subjects. Diabetologia 35:45-55

27. Desoye G, Hartmann M, Blaschitz A, Dohr G, Hahn T, Kohnen G 1994 Insulin receptors in syncytiotrophoblast and fetal endothelium of human placenta. Immunohistochemical evidence for developmental changes in distribution pattern. Histochemistry 101:277-285

28. Hiden U, Maier A, Bilban M, Ghaffari-Tabrizi N, Wadsack C, Lang I, Dohr G, Desoye G 2006 Insulin control of placental gene expression shifts from mother to foetus over the course of pregnancy. Diabetologia 49:123-131

29. LeRoith D, McGuinness M, Shemer J, Stannard B, Lanau F, Faria TN, Kato H, Werner H, Adamo M, Roberts CT Jr 1992 Insulin-like growth factors. Biol Signals $1: 173-181$

30. Cohran V, Fang J, Milio L, Smith CH, Fant M 1996 Type I insulin-like growth factor receptors in the BeWo choriocarcinoma cell (b30 clone) during cell differentiation. Placenta 17:313-320 
31. Berneis K, Keller U 1996 Metabolic actions of growth hormone: direct and indirect. Baillieres Clin Endocrinol Metab 10:337-352

32. Varvarigou AA, Petsali M, Vassilakos P, Beratis NG 2006 Increased cortisol concentrations in the cord blood of newborns whose mothers smoked during pregnancy. J Perinat Med 34:466-470

33. Jobe AH, Wada N, Berry LM, Ikegami M, Ervin MG 1998 Single and repetitive maternal glucocorticoid exposures reduce fetal growth in sheep. Am J Obstet Gynecol 178:880-885

34. Economides DL, Nicolaides KH, Campbell S 1991 Metabolic and endocrine findings in appropriate and small for gestational age fetuses. J Perinat Med 19:97-105

35. Coutant R, Boux de Casson F, Douay O, Mathieu E, Rouleau S, Beringue F, Gillard P, Limal JM, Descamps P 2001 Relationships between placental GH concentration and maternal smoking, newborn gender, and maternal leptin: possible implications for birth weight. J Clin Endocrinol Metab 86:4854-4859

36. Sebire NJ, Jolly M, Harris JP, Wadsworth J, Joffe M, Beard RW, Regan L, Robinson S 2001 Maternal obesity and pregnancy outcome: a study of 287,213 pregnancies in London. Int J Obes Relat Metab Disord 25:1175-1182

37. Hendler I, Blackwell SC, Mehta SH, Whitty JE, Russell E, Sorokin Y, Cotton DB 2005 The levels of leptin, adiponectin, and resistin in normal weight, overweight, and obese pregnant women with and without preeclampsia. Am J Obstet Gynecol 193:979-983

38. Chan TF, Chen YL, Lee CH, Chou FH, Wu LC, Jong SB, Tsai EM 2006 Decreased plasma visfatin concentrations in women with gestational diabetes mellitus. J Soc Gynecol Investig 13:364-367 